\title{
When Obsessive Compulsive Disorder Responds Only to Electroconvulsive Therapy: A Rare Case for Maintenance Electroconvulsive Therapy?
}

Sir,

Obsessive-compulsive disorder (OCD) poses significant subjective distress and bio-sociooccupational dysfunction with psychotherapy and selective serotonin reuptake inhibitors (SSRIs) as the first line of treatment. Other common pharmacological options are clomipramine and second-generation antipsychotics. Noninvasive brain stimulation techniques are experimental strategies for OCD ${ }^{[1,2]}$ Here, we present a case of resistant OCD, where electroconvulsive therapy (ECT) was the only successful treatment option.

An 18-year-old boy with the significant genetic loading of OCD in the family, presented with illness duration of 6 years, characterized by insidious in onset, continuous and progressive course with predominantly obsessions of contamination, fear and pathological doubts, the compulsion of reassurance seeking, significant anxiety, avoidance, pathological slowness, and compulsion by proxy. He was bedridden most of the time or using a wheelchair for ambulation. OCD substantially affected his personal care such as eating, micturition, defecation, and social functioning. His Yale-Brown Obsessive Compulsive Scale (Y-BOCS) score was 35 at the time of admission. Multiple adequate trials of SSRI (fluoxetine, fluvoxamine, and paroxetine), clomipramine, and augmentation with risperidone had been failed. All baseline investigations were normal. He was started on venlafaxine $300 \mathrm{mg} /$ day. Psychotherapy other than behavioral activation could not be possible due to extreme pathological slowness. Depressive episode and psychosis were ruled out. On family assessment, significant accommodation behavior was found.

In view of symptoms like passing urine and stool on the bed along with poor oral intake and significant pathological slowness, he was started on ECT. After 8 sessions of ECT (3 times a week on alternate days), his Y-BOCS score dropped down to 12. ECT was stopped in view of cognitive deficits. Soon after 5 days, he got worsened with Y-BOCS score 35. Again after re-starting ECT, the Y-BOCS scores dropped down to 16,6 , and 6 , respectively, after $2^{\text {nd }}, 4^{\text {th }}$, and $6^{\text {th }}$ ECT. He did not continue ECT due to logistic issues and worsened again 1 week after stoppage of ECT with Y-BOCS score 35 [Figure 1]. Later, the patient was followed up through telepsychiatry where he was found to be significantly worsened even with continuous intake of venlafaxine $300 \mathrm{mg}$.

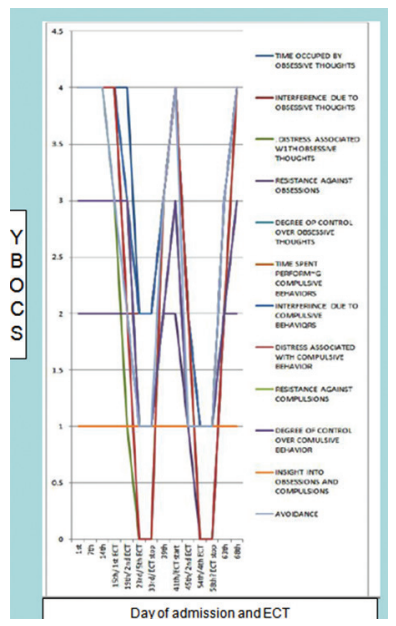

Figure 1: Symptoms resolution and electroconvulsive therapy

Only $40 \%-60 \%$ of cases of OCD show the response to combination therapy. Next line of treatment in OCD is somatic treatment such as ECT, repetitive transcranial magnetic stimulation, and transcranial direct current stimulation but evidence regarding the effect of ECT are sparse. ${ }^{[2]} \mathrm{A}$ recent systematic review published in 2015 showed that the role of ECT in the routine treatment of OCD is not significant, but it proposed the beneficial effects of ECT in OCD under special circumstances. ${ }^{[1]}$ Most of the cases who improved on ECT were benign. Furthermore, evidence of the positive responses to ECT were more commonly described in recent studies than the older one. ${ }^{[1]}$ Here, in our case, the patient was tried with multiple SSRIs and clomipramine but did not show any response where ECT surprisingly benefited the patient by reducing the obsessions and related dysfunctions. Even though ECT has poor evidence as a treatment of OCD, we can consider it in such cases where we do not have any other options to implement. As our patient maintained improvement while on ECT but worsened soon after the stoppage, maintenance therapy of ECT in OCD can be considered in special cases. Maintenance ECT has the potential of preventing implementation of invasive procedure like neurosurgery when OCD becomes refractory to treatment.

\section{Declaration of patient consent}

The authors certify that they have obtained all appropriate patient consent forms. In the form the patient(s) has/have given his/her/their consent for his/ her/their images and other clinical information to be 
reported in the journal. The patients understand that their names and initials will not be published and due efforts will be made to conceal their identity, but anonymity cannot be guaranteed.

\section{Financial support and sponsorship}

Nil.

\section{Conflicts of interest}

There are no conflicts of interest.

Adesh Agrawal, Soumitra Das, Jagadisha Thirthalli

Department of Psychiatry, National Institute of Mental Health and Neuroscience, Bengaluru, Karnataka, India

Address for correspondence: Dr. Soumitra Das, Department of Psychiatry, National Institute of Mental Health and Neuroscience, Bengaluru - 560 029, Karnataka, India. E-mail: soumitra_nimhans@yahoo.com

\section{REFERENCES}

1. Fontenelle LF, Coutinho ES, Lins-Martins NM, Fitzgerald PB, Fujiwara $\mathrm{H}$, Yücel $\mathrm{M}$, et al. Electroconvulsive therapy for obsessive-compulsive disorder: A systematic review. J Clin Psychiatry 2015;76:949-57.
2. Janardhan Reddy YC, Sundar AS, Narayanaswamy JC, Math SB. Clinical practice guidelines for obsessive-compulsive disorder. Indian J Psychiatry 2017;59:S74-S90.

This is an open access journal, and articles are distributed under the terms of the Creative Commons Attribution-NonCommercial-ShareAlike 4.0 License, which allows others to remix, tweak, and build upon the work non-commercially, as long as appropriate credit is given and the new creations are licensed under the identical terms.

\begin{tabular}{|l|l|}
\hline \multicolumn{2}{|c|}{ Access this article online } \\
\hline Quick Response Code: & Website: \\
& www.ruralneuropractice.com \\
\cline { 2 - 2 } & \\
\hline
\end{tabular}

How to cite this article: Agrawal A, Das S, Thirthalli J. When obsessive compulsive disorder responds only to electroconvulsive therapy: A rare case for maintenance electroconvulsive therapy? J Neurosci Rural Pract 2018;9:450-1.

C 2018 Journal of Neurosciences in Rural Practice | Published by Wolters Kluwer - Medknow 